\title{
Beliefs and practices about reproductive tract infections: Findings from a series of Philippine FGDs
}

\author{
Marilou Palabrica-Costello \\ Carmeli Marie Chaves \\ Chona R. Echavez \\ Cecilia Conaco \\ Mariano Santiago
}

Follow this and additional works at: https://knowledgecommons.popcouncil.org/departments_sbsr-rh

Part of the Health Services Research Commons, and the International Public Health Commons How does access to this work benefit you? Let us know!

\section{Recommended Citation}

Palabrica-Costello, Marilou, Carmeli Marie Chaves, Chona R. Echavez, Cecilia Conaco, and Mariano Santiago. 1997. "Beliefs and practices about reproductive tract infections: Findings from a series of Philippine FGDs," Asia and Near East OR/TA RTI Integration Project Report. Manila: Population Council. 
RTI Integration Project Report No. 1

BELIEFS AND PRACTICES ABOUT

REPRODUCTIVE TRACT INFECTIONS:

FINDINGS FROM A SERIES

OF PHILIPPINE FGDs

\title{
PHILIPPINES
}

\author{
Marilou Palabrica-Costello \\ Carmeli Marie Chaves \\ Chona Echavez. \\ Cecilia Conaco \\ Mariano Santiago
}

USAID Contract No. DPE-3030-Q-00-0023-00

Strategies for Improving Family Planning Service Delivery

\section{FAMILY PLANNING OPERATIONS RESEARCH AND TRAINING PROGRAM (FPORTP)}

Population Council, Manila

in collaboration with

the Department of Health

\section{ASIA \& NEAR EAST OPERATIONS RESEARCH AND TECHINICAL ASSISTANCE PROJECT}

May 1997 


\section{ACKNOWLEDGEMENT}

The researchers wish to acknowledge the cooperation of the following persons in the conduct of the FGD:

1. Kamuning Barangay Captain Felicisimo Espiritu

2. Lapasan Barangay Captain Teodulfo Lao, Jr.

3. Mayor Huberto Paurom of Jasaan, Misamis Oriental

4. Ma. Aurora Magsalay and Nathanael Paalam who facilitated the FGDs in Cagayan de Oro and Misamis Oriental

5. Clemente Manaog, Ma. Odilyn de Guzman, Felicito Magsalay Jr. and Christine Unabia who documented and transcribed the proceedings.

Most of all, we owe our gratitude to the men and women who took time out to join our focus group discussions. This report would not have been possible without them. 


\section{TABLE OF CONTENTS}

\section{Page}

ACKNOWLEDGEMENT

INTRODUCTION 1

STUDY FINDINGS 4

Concepts of Health and Sickness 4

Knowledge and Beliefs about RTIs 5

Social Dimensions of RTIs 9

Preventive and Curative Practices $\quad 11$

$\begin{array}{ll}\text { POLICY IMPLICATIONS } & 15\end{array}$

$\begin{array}{lr}\text { REFERENCES } & 17\end{array}$ 
RTI Integration Project Report No. 1

\title{
BELIEFS AND PRACTICES ABOUT REPRODUCTIVE TRACT INFECTIONS: FINDINGS FROM A SERIES OF PHILIPPINE FGDs
}

\author{
Marilou Palabrica-Costello \\ Carmeli Marie Chaves \\ Chona Echavez \\ Cecilia Conaco \\ Mariano Santiago
}

\section{INTRODUCTION}

The past decade has been characterized by an increasing concern about the medical, social and economic problems associated with Reproductive Tract Infections, or RTIs. The goal of preventing and curing RTIs is now being prioritized by public health agencies in the developing world. Several studies have found that the true incidence of RTIs can be alarmingly high, often several times higher than that identified by conventional health statistics (Younis, et al, 1993; Wasserheit, et al, 1989; Bang, et al., 1989). This discrepancy occurs in large part because many women are either unaware of their infection, inclined to regard it as a "normal" state of affairs, or ashamed to consult a health practitioner on this unusually sensitive topic. As a result, efforts to control the spread of RTIs have frequently proven unsuccessful. This is particularly unfortunate since RTIs can result in the discontinuation of family planning use, in severe bodily dysfunctioning (e.g. sterility), and in an increased probability of contracting AIDS or some other STD.

Very little research has been done on the problem of RTIs in the local context. One recent study which was conducted in Davao City (Sanchez and Juarez, 1994) has confirmed the widespread existence of this problem within a fairly typical Philippine setting. Data from the 1993 Philippine Safe Motherhood Survey (National Statistics Office and Macro International, 1994) are also of interest insofar as they demonstrate that nearly two-thirds of all women suffering from abnormal vaginal discharge do not 
seek professional help for this condition Even so, it is clear that much more needs to be understood about these conditions, especially with regard to their social and cultural underpinnings. It would thus be particularly helpful for program managers if we could delineate more clearly the knowledge and beliefs now being held about RTIs. We also need to know more about the way in which these illnesses are viewed by the community, about traditional practices for preventing and curing RTIs, and about the results of ongoing public health initiatives designed to deal with these conditions.

The present study represents an initial effort along these lines. It utilizes a qualitative research technique known as focus group discussions (FGDs) as a means of stimulating people to speak up on this particular subject. Thus, while we will not be able to show a precise statistical profile of the study respondents, their ideas and their behavior, we should be able to get a first-hand glimpse of the ways in which RTIs are perceived and responded to by a group of "typical" Filipinos.

As the name implies, the basic technique involved in conducting an FGD is to set up a small group discussion, usually involving about six to ten participants. The discussants are joined by a moderator who controls the flow of the conversation by means of some previously prepared guide questions on the topic of interest. Participants are free to speak up at any time during the course of the FGD although a practiced discussion leader will find ways of encouraging some of the less talkative ones to share their ideas and to prevent others from completely dominating the proceedings.

Participants are generally assigned to groups which are more-or-less homogeneous along sociodemographic lines. In the present instance, for example, this means that they have been matched with one another by community of residence, age, and sex. Social class composition in this study was also somewhat uniform in the sense that nearly all of the respondents came from modest economic circumstances.

FGDs were held in three study communities. These included the highly 
urbanized context of the National Capital Region (Barangay Kamuning, Quezon City, Metro Manila); a lower class neighborhood (Barangay Lapasan) in the medium-sized city of Cagayan de Oro; and the rural community of Jasaan, Misamis Oriental. Four FGDs were held in each of these settings, with one each being composed of younger women (twenties and early thirties), older women, younger men, and older men. All of the sessions were tape recorded, so that transcripts could then be prepared. Taken together, the transcripts comprise more that 270 pages. In this report we will try to summarize the major themes that have emerged from a detailed review of these documents. 


\section{STUDY FINDINGS}

\section{Concepts of Health and Sickness}

The FGDs began with a general discussion of the factors which can be used to distinguish between a person who is healthy and one who is ill. Among the older female respondents, two criteria--physical appearance and energy level--were stressed. According to these women, a healthy person has a strong body with good skin tone (rosy cheeks, pinkish skin) while excessively pale persons are sickly. Healthy people are also energetic and active, with this latter concept being extended to include sexual activity. Sickness, infection and feeling weak or tired are all associated with illness.

Younger women agreed with most of the above depictions. They, too, feel that being sexually active and having a big sexual appetite were signs of good health, particularly for distinguishing between sick and healthy males. A 30-year old married woman from a rural community in Southern Philippines explained what she meant when she said that a healthy male is askil (active) or abtik (energetic): "...you will know [that a man] is healthy because he often engages in sex."

Indeed, healthy men were portrayed by this group as more-or-less conforming to the "macho" stereotype--they are big and muscular, able to lift heavy objects, able to perspire freely, and not liable to be out of breath when engaged in some sort of exercise.

For older men a similar picture again emerges. Interestingly enough, they do not distinguish closely between "big" men and "fat" men--both are equally interpreted (according to their standards) as being exemplars of good health.

Older women and men in three (out of 12) focus group sessions considered plumpness a sign of good health. Some, however objected to the association of plumpness to good health. A 44-year old businessman claimed: "Naa man gihapoy 
tambok nga dili himsog. (There are fat people who are not healthy.)" And a 42-year old housewife asserted: "Naa man say ubang niwang nga aktibo ... dili luya... (There are skinny people who are active... not weak...)" The objections raised were summed up by a man in his 40 s when he declared: "...ang taong malusog ay hindi masyadong nakikita sa panlabas na kaanyu-an lamang...(the manifestations of a healthy person are not only seen in his [or her] outward appearance...)" It surfaced from the discussions that health does not only pertain to physical wellbeing but to soundness of mind. "Matalino" (intelligent) and "may wastong pag-iisip" (right thinking) came up as descriptions of a healthy person.

Conversely, ill health is seen by them as being connected to being weak or thin, having a low resistance level, lacking sleep, and engaging in too many "vices" (drinking, smoking, using drugs).

Younger men, too, mentioned most of the above themes. They emphasized that the capability of begetting a child is a sign of good health. When asked who a healthy person is, a 27-year old teacher answered: "...ang tawong makabuhat ug bata (one who can make a baby)." He added that a sickly person is: " ... luya, luya...dili makahimo ug bata ([one who is] weak, weak...cannot beget a child)."

For them, a healthy lifestyle entails good diet, frequent exercise, and a somewhat longer list of vices (gambling and "women" are included along with drugs and alcohol). Men who are not healthy are seen by this group as being thin, pale, weak, short of breath, without much appetite and unable to beget a child.

\section{Knowledge and Beliefs about RTIs}

In general, females knew more than males about the different types of RTIs. Discussions tended to focus first on those conditions of greatest personal concern to the group in question--e.g. uterine infections and cancers among the women, STDs and AIDS for the men. 
Uterine infections were stressed by both groups of women. In most cases, though, they did not know the technical (scientific) name for these conditions. Symptoms include fever, chills and bleeding. Several alleged causes were mentioned, including an overly early return to sexual activity after the birth of a child, large family size (too many births weaken the uterus and make it prone to infection), use of the IUD, and having an abortion.

Another RTI variety was described generally as itching of the female genitalia. Some women said they experienced this just before their menstruation, others just after. In the latter case the immediate cause was said to be either the menstrual blood or the use of sanitary napkins, which are hot and do not allow the genitalia to "breathe." Other causes include the use of unclean water for washing oneself, dirty underwear, allergy to birth control pills and use of the IUD. A 21-year old woman attributed the cause of RTI to the presence of micro-organisms which multiply very fast when one wears tight-fitting pants. She said:

Kung magsuot ka ng masisikip na pantalon, kung saan may masamang fungi yata yon o protozoa, basta masasamang bacteria na mahilig sa basa. ... Doon sila nag-grow tapos kung magsuot ka ng tight o fitting [pants] kaya lalo silang dumadami. (If you wear tight-fitting pants where bad [infectious] fungi or protozoa, or bad bacteria that thrive in wet environment are present... ...They grow right there and if you wear tight-fitting [pants] the more the organisms will multiply.)

Certain sexual practices can also be at fault here, including a failure on the part of the man to clean himself before sex (or for the women to do so afterwards) and the inserting of fingers or certain sex gadgets into the vagina. Women also mentioned that men, especially Filipino contract workers from the Middle East used the sex gadgets during sexual intercourse that may have caused RTIs: vibrators, bolitas or tiny metal balls surgically embedded in the man's penis, and pilik-mata ng kambing $o$ kabayo (eye lashes of goats or horses).

Several women from both age categories also focused on menstrual-related conditions, e.g. dysmenorrhea, menstrual delays or overly heavy flows. Sour or acidic 
foods and exposure to the rain or to cold air were seen as tending to bring on dysmenorrhea.

Focus group participants raised that both women and men can experience an infestation of lice in their genital area. This happens when the person has sex with someone already afflicted with this condition (e.g. men who patronize prostitutes). Symptoms include itchiness, flaking skin, swelling, lacerations and bad odor.

Uterine cancer was emphasized more by women than by men. This seems to be closely linked in the minds of several respondents with the use of certain forms of family planning (IUD, DMPA, ligation, the pill) or to unclean blankets and bedding. Some women narrated cases of IUD users they knew or heard of who died of uterine cancer. According to them, these women did not go back for check-up after IUD insertion. A 33-year old woman related to the group what she heard,

...patay to siya ... 18 years gyod wala niya gipakuha ang iyang IUD... unya wa say check-up check-up...(...she died... for 18 years the IUD was not removed...never had a check-up [after the insertion]...)

All groups held extended discussions on STDs and AIDS. Among the older women, syphilis, gonorrhea and herpes were all mentioned but there seemed to be some confusion among the participants as to the exact distinctions among these diseases. Several men had not only heard about gonorrhea but had experienced it as well. They said that the major symptoms of this condition included pain in the abdomen and the penis, painful urination and pus in the urine. Syphilis results in painful urination and sores on the penis. (A few women pointed out as well that STDs could result in infertility on their part or certain conditions affecting the newborn child.)

The men from Quezon City, a highly urbanized area, were more knowledgeable in identifying the different types of STDs than the men from Cagayan de Oro City and Misamis Oriental. The latter were inclined to lump the 
different types of STDs in the term sira or nasira (a Tagalog term which means 'broken'). They were familiar, though, with the manifestations of persons afflicted with STDs. A 28-year old, married government employee aired his confusion:

Kuan, kining STD ba,...tingali mao ni siya ang mga syphilis, gonorrhea, scabies, lice? ...Wala kaayo ko kadungog ana. Kasagaran mao ra gyod na nga nasira lang ug wala nay lain pa. (...This STD ...perhaps this covers syphillis, gonorrhea, scabies, lice? I did not come across [these terms]. I often hear only the term nasira [for these diseases].

Men and women alike agreed that STDs are generally transmitted through visits to a commercial sex worker who is already infected with the disease. Some felt as well that one could contract either AIDS or an STD from unclean toilet seats or shared eating utensils.

When pressed to think of additional types of RTIs, several groups mentioned urinary tract infections. These are believed to be due to such factors as frequent sexual intercourse, delayed urination, failure to wash oneself after urination, washing with dirty water, and overconsumption of soft drinks or "junk food."

Sterility, infertility and impotence were all mentioned as well, although only in the female FGDs. Some women are said to be unable to bear a child due to the position of their uterus. This may be an inborn characteristic or a condition brought on by overwork while the woman was still single. In some cases this can be treated by massaging the uterus.

Infertility in men could be due to low sperm count, malnutrition, having eaten too many sweets, taking too many antibiotics or a history of certain predisposing diseases (mumps, certain STDs).

A final category worth mentioning relates to contraceptive-related conditions. The IUD was seen as particularly likely to cause one or another problem in this regard--e.g. intrauterine bleeding, scraping of the man's penis (this can supposedly be caused by the nylon string attached to IUDs) or infections (if the insertion is not 
done under sanitary conditions). Pills were thought to bring about uterine cysts and cancers while vasectomy causes impotence and/or homosexuality. A few respondents felt that condoms could lead to infections, either when they are used repeatedly or in cases when they are "left inside" the vagina.

\section{Social Dimensions of RTIs}

kahadlokan (to be feared), likayan/iniiwasan (to be avoided), ubos ang pag-tan-aw (to be looked down), tambag-tambagan (to be given advice), intindihin (to be understood), kaluyan/kaawaan (to be pitied), atimanon ug istoryahon/kausapin... (to be attended and talked to...)

- discussants' perceptions of people afflicted with RTI

Reactions to the different RTIs appear to be context dependent. Men tended to say that they would be helpful or sympathetic if one of their friends contracted an STD. In the case of strangers, especially women, though, the tendency is to shun the infected person, for fear of being contaminated. The following are the men's reactions:

Kung yung taong 'yon ay kaibigan kong tunay papayuhan ko siya ng maganda nang sa gayon... hindi na siya mahirapan. Kung hindi kaibigan 'yung nagtatanong sa 'yo ipahiwatig mo 'yung nalalaman mo...Hindi mo naman lalayuan...Lalake din tayo...(If the person affected is a friend, I will give him good advice so that his problem will be solved and he will no longer suffer. ...If the person is not a friend... will tell him what I know [of the disease]... I won't avoid him since I am also a man and I understand...

Kung babae...yan eh mahirap...kasi hindi mo alam kung tulo o AIDS... (If a woman...that's difficult since I'm not sure if it is gonorrhea or AIDS.)

Kung babae...huwag kang lumapit, kung maari itaboy mo siya...( 
If a woman... don't go near; if possible send her away...)

A few women noted the stigma attached to RTIs in general and STDs in particular. For men, though, there was a tendency to view STDs as a more-or-less normal occurrence in the life of a man. The general feeling seemed to be that "these things happen" and that the main concern should be finding a way to treat them as soon as possible. However, men did not adopt the same attitude when their wives are the ones infected. A man in his mid-30s said:

Ako, di ko matanggap. Iba ang kinalakihan ko... hindi ko matanggap. (I can not accept it. I have a different ubringing... I can not accept it.)

Both sexes were less sanguine about the impact of RTIs (particularly STDs) upon the marital relationship. Should this happen it would definitely put a strain upon their marriage and cause of loss of trust on the part of the wife. Suspicions would be raised and quarrels would most likely result.

Indeed, there was widespread agreement that communication processes concerning RTIs and STDs will nearly always be quite difficult. Women typically doubted if their husbands would be completely open on this subject, probably for good reason. Most of the male informants admitted openly that they would not want to tell their wife if they contracted an STD. They felt that this would only embarrass them and cause trouble within the family. They would rather talk things over with a close friend or a doctor.

Some of the younger men claimed that they would tell their wife, but only after they had been cured. A few said they would be open about this as a way of ensuring that their partner would not contract the infection, too. Others, though, said only that they would try to protect their wife by finding ways to avoid having sex with her.

In short, the whole topic appears to be one which engenders embarrassment, subterfuge, dishonesty, suspicions and mutual recriminations. (Most wives said they would be angry if their husband contracted an STD. For their part, some of the older 
males said they would beat their wife if she were to be the one caught in an apparent infidelity.) As such, it seems likely that most RTIs will involve more than just the single individual who may happen to be infected. In many instances, no doubt, the illness will be passed on to the wife (or husband) as well.

\section{Preventive and Curative Practices}

Results from this study may be taken to indicate that disease-prevention campaigns which rely exclusively or heavily upon increased use of condoms will have a difficult time succeeding. Both male and female discussants held strongly negative reactions toward this type of family planning. At best, condoms are disliked because they are said to diminish sexual pleasure. Beyond this, condoms are variously described as causing pain (especially for women, since it acts to lessen vaginal lubrication), encouraging interspousal distrust, and as being both unreliable and "disgusting". There appears to be a widespread belief that condoms don't always work because they might have holes in them or might come off during intercourse. Several couples had tried to use condoms at one point or another but nearly all discontinued its use soon afterwards. A 39-year old woman attested that she became pregnant 'with using condom' :

Gisuwayan man to namo...mao ra to... kay pagpuwas sa condom walay sulod, nabuslot diay. Na maburos gyod ko ani. Naburos gyod... (We tried using condom before but we discontinued. [After we had sex,] when the condom was removed there was nothing inside... there was a hole. I was afraid I'll get pregnant. I surely became pregnant...)

A male discussant from Quezon City confided that he has not used condom ever:

Nadidinig ko lang condom.. pero di ko naranasang gumamit ... Sabi nila safe sex, ang problema you cannot feel sex kasi

nakabalot... ( I have heard of condom but I haven't used it...They say it is 'safe sex'. The problem is you cannot 'feel sex' because [the penis] is wrapped...) 
Other preventive practices included (for the women) the maintenance of good personal hygiene, staying away from contact with an infected person, and coming to the health center for a regular PAP smear. It is perhaps instructive that this latter suggestion was made only by older women from the most urbanized context (i.e. Quezon City).

Men realize that the best way to avoid infection would be to refrain from having illicit sex with prostitutes. There seems to be an underlying assumption in this case, though, that perpetual fidelity to one's marriage partner will be a difficult and perhaps unrealistic standard to live by. As such, men will often adopt various fallback strategies, such as "being careful" (use a condom, take steps to insure that the woman is "clean"), practicing good hygiene and putting the proper treatment strategies into effect once it is clear that an infection has been contracted.

The men showed themselves to be quite knowledgeable when it came to the question of describing these treatments. Modern medicines (antibiotics in particular) were favored and the names of several drugs (e.g. Remactin) were specifically mentioned. Some traditional methods were described as well: the heated young coconut; a special type of bitter herb ("panyawan") which may be brewed into a tea or used as a poultice on the abdominal area; covering the male sex organ with hot sand at noon time; drinking buco (young coconut) juice to wash away the infectioncausing bacteria. In cases where lice have been contracted, the pubic hair should be shaved and the area then subjected to an application of gasoline or paint thinner.

Female respondents likewise mentioned several of the above strategies. The preferred treatment for vaginal itching was to wash the infected area carefully. This can be done using rubbing alcohol, vinegar, calamansi solution or water in which young coconut leaves have been boiled.

Taking antibiotics was the recommended cure for someone with syphilis or gonorrhea. The recommendation came from either a doctor or a friend who experienced the disease before. Placing a beef poultice on the sex organ or inserting 
the penis into a heated young coconut (a hole is bored for this purpose) are believed to be effective cures for this condition.

In cases where a health specialist would have to be consulted, there was a general consensus among both the men and the women that this should be a doctor rather than a traditional healer or a licensed midwife. In general, women would rather go to a female doctor since a physical examination would be required. Likewise, the men would rather go to a male practitioner. Even more important than the doctor's gender, though, would be his or her degree of specialization and knowledgeability. For example, the women felt strongly that the doctor consulted should be a specialist-i.e. an obstetrician-gynecologist. There were others who were resigned that they were in a 'no choice' situation, especially in public hospitals or health centers. A young married woman commented, "We do not own the hospital or health center; if a male doctor is on duty, there's not much we can do..." In the group of younger men, someone also said,

ma-babae o lalake ang doktor basta magamot ang karamdaman...(either a female or male doctor for as long as the disease will be cured...)

Men and women alike tended to prefer a somewhat older doctor, on the assumption that he or she would thereby have more experience in treating RTIs. A few pointed out that a younger doctor might have learned up-to-date information on the topic, but most felt that they would not want to be "practiced on" by such a person.

Certain other characteristics of a good doctor were mentioned by the respondents, particularly the younger women. Doctors should be "gentle", "sensitive" and "not too strict." It also helps if the doctor will be familiar enough to the patient that she can feel close to him or her.

Comparisons between private health clinics and the public sector health centers were generally decided in favor of the former. Specific complaints mentioned with regard to the LGU clinics were that their personnel were less competent and less 
accommodating, that waiting times were longer, and that they could not offer sufficient privacy. Private practitioners were perceived as offering more in the way of privacy, confidentiality and competency. The sole drawback in this case was, of course, that they also charge higher fees. However, a woman in her 40s advised:

Kung minsan, kung mayron ka namang sapat na pera, sa private ka na. Kasi sa private asikaso ka agad kung may pera. (Sometimes, if you have enough money, go to a private [doctor]. Because in the private [clinic] they will take care of you at once if you have the money.)

One of the suggested methods for diagnosing RTIs is to use a "risk assessment" questionnaire that asks several very personal questions about the client's sex life and that of his or her partner. Reactions to the prospect of being subjected to this sort of experience were generally positive, all things considered. Most felt that they would not object to being asked these questions, as long as it would somehow help them to be cured. This, of course, should be done in the proper manner with the interview being conducted in private and the questions being asked in a sensitive manner, so as to lessen any chances that the patient would feel embarrassed or humiliated. 


\section{POLICY IMPLICATIONS}

Several implications for program managers involved in the treatment and prevention of RTIs would appear to flow from the findings noted above. To begin with, knowledgeability levels about these diseases would appear to be only moderately high at best. Public health campaigns to increase awareness about the different conditions and their proper treatment are very much needed. Preventive techniques are little understood and generally not followed while treatment regimes are in many cases based solely upon nonscientific, traditional practices. Attitudes toward condom use are generally unfavorable except perhaps for a certain willingness to adopt these in cases where a commercial sex worker is being patronized. Rumors and misconceptions about the deleterious health consequences of adopting such modern family planning (FP) methods as the IUD, oral contraceptives, and DMPA are also quite widespread. These beliefs must surely present a major obstacle to the goal of increasing FP use among married couples in the Philippines.

Several specific complaints were also lodged against the public health system. Most respondents had doubts about the competence of the health care workers associated with the LGU clinics. This was particularly true for BHS-level personnel (i.e. midwives) insofar as there was a strong preference for treatment by licensed doctors. Even in cases when a public sector doctor could be consulted, however, some doubts still remained. There were also more than just a few fears concerning the lack of privacy and confidentiality found in many of the LGU health centers. Any successful effort to combat RTIs will thus have to address these concerns directly.

Stigmatization of RTI patients does not appear to be a major problem in our

three study areas. Even so, sensitive questions about marital fidelity, guilt and interspousal communication most certainly do come into play when a married person is found to have contracted an STD. Most men admit openly that they therefore prefer to deal with this issue by consulting a close friend or a doctor, all the while avoiding any mention of the subject to their wife. As such, chances are that repeated mutual reinfections can and will occur. 
Counseling mechanisms for encouraging and facilitating partner notification should therefore be developed. Public health messages designed for the purpose of self-diagnosis may also help as well to reach those women who have been infected by their partner without knowing how to interpret the resulting symptoms.

Public health initiatives might also be directed towards young people, too. One important component of such efforts might be to encourage young men to realize that one can indeed lead a normal sex life without having to patronize commercial sex workers. (At present, the Filipino male subculture seems to take a rather different stance on this question.) As a last resort, of course, condom use can be encouraged among those males who insist on visiting CSWs.

To a large extent this report has concentrated upon those RTIs which are sexually transmitted. This, of course, is a bit misleading since there are other diseases of this variety which can be brought about by endogenous or iatrogenic causes. The problem in this case, though, is that the great bulk of our discussants seem to know little or nothing about such conditions. Herein lies a final challenge for officials involved in public health campaigns. In order to be treated successfully, these conditions will have to be diagnosed. At present, this is just not happening on anything like an appropriate scale and magnitude. (An affiliated study of health center activities in Jasaan and Cagayan de Oro, as was also conducted by the Population Council, found that most of these clinics are now treating only a handful of such cases every year.) No doubt, a major reason for this lies in the fact that most women with RTIs don't really realize just how potentially serious their condition has become. A stronger effort to increase public awareness about this vital issue is therefore clearly needed. 


\section{REFERENCES}

Bang, R.A. et al. 1989. High Prevalence of Gynecological Diseases in Rural Indian Women. The Lancet 1: 85-88.

Bhatia, Jagdish C. and Cleland, John . 1995. Self-reported Symptoms of

Gynecological Morbidity and Their Treatment in South India. Studies in Family Planning 26: 203-216.

National Statistics Office and Macro International Inc. 1994. National Safe Motherhood Survey 1993. Calverton, Maryland: NSO and MI.

Sanchez, Rosena D and Maribeth P. Juarez. 1994. Community-Based Research and Advocacy in Reproductive Health among Urban Poor Women in Davao City. Davao City: Development of People's Foundation.

Wasserheit, Judith N., et al. 1989. Reproductive Tract Infections in a Family Planning Population in Rural Bangladesh. Studies in Family Planning 20: 6980.

Younis, Nabil, et al. 1993. A Community Study of Gynecological and Related Morbidities in Rural Egypt. Studies in Family Planning 24: 175-186. 